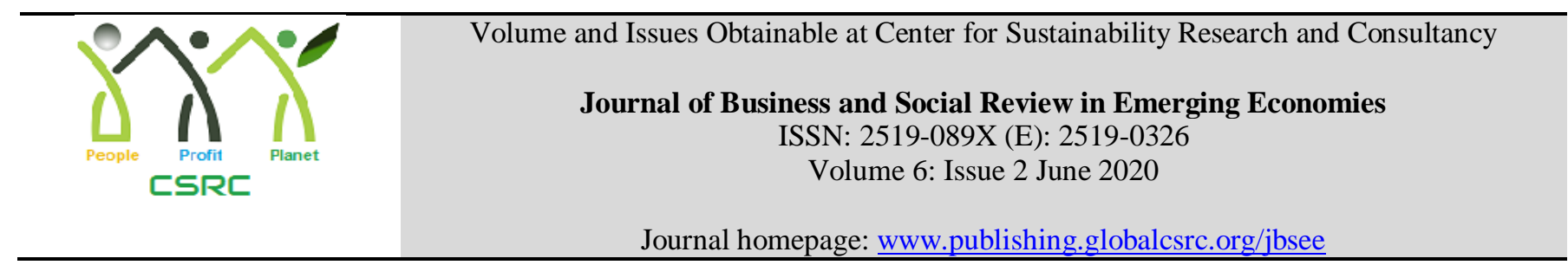

\title{
Quality and Usefulness of Data: Investigating the Discrepancies in Pakistani Public School Data and Implications for the Way Forward
}

\author{
${ }^{1}$ Syed Abdul Waheed, ${ }^{2}$ Ghulam Qambar, ${ }^{3}$ Nadia Gilani \\ ${ }^{1}$ Assistant Professor, Department of Educational Research \& Assessment, University of Okara, Pakistan, \\ s.a.waheed@uo.edu.pk \\ ${ }^{2} \mathrm{PhD}$ Scholar, Department of Educational Research \& Assessment, University of Okara, Pakistan \\ ${ }^{3}$ Assistant Professor, Department of Teacher Education, University of Okara, Pakistan
}

\section{ARTICLE DETAILS}

\section{History}

Revised format: May 2020

Available Online: June 2020

\section{Keywords}

Usefulness of data, school

performance indicators, decision-making, district

ranking system, school data,

Pakistan

JEL Classification

M1, M12

\begin{abstract}
The quality school data contributes to reliable decision making in the school education system. The data provided by different organizations should be consistent, valid and complement each other to establish its quality and usefulness. The present study purports to explore the discrepancies among the different data sources that have implications for improving the quality and usefulness of school data. The available school data from various sources of school education was used followed by an explanation through semi-structured interviews with the teachers employing an explanatory mixed methods design. The results revealed that there were substantial discrepancies among varying school data sources that did not reflect the 'real' work efficiency of the schools and the school authorities excessively rely on such data for significant decisionmaking. This leads to a risk of bringing meaningless reforms in the school education system. These discrepancies found in the school data sources have implications for improving the existing practices of data collection and a performance appraisal mechanism in schools.
\end{abstract}

(C) 2020 The authors, under a Creative Commons Attribution-

NonCommercial 4.0

Corresponding author's email address: s.a.waheed@uo.edu.pk

Recommended citation: Waheed, S. A., Qambar, G., Gilani, N. (2020). Quality and Usefulness of Data: Investigating the Discrepancies in Pakistani Public School Data and Implications for the Way Forward. Journal of Business and Social Review in Emerging Economies, 6(2), 869-882

\section{Introduction}

Decision making in today's organizational environment involves large data volumes after the rapid proliferation of computer-based information systems (Shankaranarayanan \& Cai, 2006). Educational decision-makers are also forced to become more responsive to data as they have access to large data sets anywhere in the world. In such an environment, it has become significant for decision-makers to assess the usefulness of the available data. The data to be used in policy formation and decision making should have an acceptable quality. One of the ways to assess data quality is through attributes or dimensions. Some certain characteristics and parameters determine the quality of data. Those parameters include appropriateness, time of data recording, relevance, integrity, correctness, conformity, consistency, safety and protection, composition, effectiveness, competence, and convenience of data retrieval (Miller, 1996). Data quality is a multidimensional concept as presented in the literature. Nevertheless, the dimensions which are expressed more often are correctness, integrity, conformity, consistency and times at which data was recorded. (Pipino, Lee, \& Wang, 2002; 


\section{Wand \& Wang, 1996; Wang, Ziad, \& Lee, 2006).}

The concept of using data to make decisions is practiced successfully in different industries and manufacturing firms such as total quality management, organizational learning, and continuous improvement. In the education sector, this concept is adopted keeping in view its success in other industries (Juran, 1988; Senge, 1990; Shewhart \& Deming, 1986). This emphasizes that organizational performance can be improved and enhanced by effective utilization of various types of data including input data such as material cost, process data such as production rates, outcomes data such as defects rate and satisfaction data such as customer opinion and satisfaction. In education, the roots of datadriven decision making lies in the 1980s in the debates about measurement-driven instruction (Popham, 1987; Popham, Cruse, Rankin, Sandifer, \& Williams, 1985).

Regarding decision making in educational settings, Mandinach, Honey, and Light (2006) argued that it depends upon four types of data including input data, process data, outcome data, and satisfaction data. Input data involves expenditures or demographics of students; process data involves financial operation or quality of instruction data; outcome data involves dropout rate and students' achievement score and satisfaction data involves opinions from community, parents, students, and teachers. Also, Marsh, Pane, and Hamilton (2006) explained that the presence of raw data is useless until organized and combined with the full understanding of the situation gained through a process of analysis and summarization of data to yield information. When data users synthesize information, apply their judgments to prioritize them and the relative merits of possible solution.

This is the point where different types of decisions are made based on this actionable knowledge. The decisions may involve setting goals and assessing progress towards the achievement of those goals, need assessment of team and individuals (e.g. support for low performing students and schools, etc.), evaluating the effectiveness of different practices going on, assessing progress towards meeting stakeholders' needs, reallocation of resources or improvement initiatives to improve outcomes. To gain fruitful results in data-driven decision making, the availability of high-quality data is the basic requirement. Without that data, it may lead to misinformation and may lead to invalid inferences. Misleading data can lead to erroneous conclusions hence provides a basis for useless decisions (Mandinach, Honey, \& Light, 2006; Marsh, Pane, \& Hamilton, 2006).

Nowadays, managing and improving performance in school education and higher education sectors based on data collected on different performance indicators is so widespread that one cannot imagine educational life without using them appropriately. Data is collected continuously about the working capacity of schools to control the systems, develop new methods and to encourage innovations (Dalton, 2017; Muriel \& Smith, 2011; Ozga, 2003). The government of Punjab, Pakistan created the Punjab Education Sector Reform Program (PERSP) in 2003 under the school education department with an aim of access to school data, quality enhancement and improving educational administration. It initiated Punjab School Reforms Roadmap in 2010. It performed outstandingly in different initiatives including provision of new books, recruitment of teachers and scholarships for female students with a special focus on data collection to measure the effectiveness of the roadmap. PESRP also introduced the Program Monitoring and Implementation Unit (PMIU). It was its responsibility to administer the policies through a rigorous and consistent approach towards data collection on different performance indicators.

Some different performance indicators include attendance of teachers and students, cleanliness and hygienic environment of a school, number of visits of different administering officers of the district, school facilities and attendance of other staff members and teachers. Quantitative data about different indicators are collected after each month by PMIU. PMIU manages the collected data and publishes quarterly district rankings (PERSP, 2018). The ranking of districts is based on the data provided by PMIU (PERSP, 2018). Indicators that are calculable are more important and crucial for the public and those who make policies because they appear to be straightforward and reliable. School members including teachers, students, and other staff can adapt themselves easily according to these indicators. The advancement of these indicators can be presented in graphs to show trends over time. Nevertheless, the quality of data is open to many questions in terms of its use (Qambar, Farooqi, \& Ather, 2018). The present data seems inadequate in describing the complexities of our education system (Alif Ailaan, 2017). If the method adopted to measure the performance of schools fails to provide accurate information then it results in unreliable decision making (Bohte \& 
Meier, 2000; Bouckaert \& Peters, 2002).

Our focus in this study is on the quality of data in the perspective of educational performance indicators provided through PMIU and PEC (Punjab Examination Commission) examinations and this will also lead to some aspects of an effective strategic information system needs for an educational system in this era of information technology, making it relevant to the field of strategic information management. This paper addresses the availability of useful data used for decision making in the education department with an understanding of data quality issues. The approach used in this study has much in common with already conducted studies in the field of data processing (Qambar, Farooqi, \& Ather, 2018). The present study does not delve into the problem by setting data quality dimensions as a benchmark. By conducting empirical research, the researchers attempted to explore some flaws in the available database and to further explore the depth of these issues by conducting interviews of teachers working in the field.

\section{Purpose of the Study}

The main aim of this study was to find out the usefulness and quality of data provided by different data sources organized and maintained by government organizations on educational performance indicators relative to some private organizations and general teachers' opinions. Therefore, we have attempted to investigate an indigenous problem of the school information system which has been getting worse and deeper in the school system of the province of Punjab, Pakistan for the last few years affecting the overall decision-making process continuously. The study aimed to suggest how an invalid and unrealizable school data can lead to inappropriate decisions by the higher authorities and can affect the stakeholders in the education system. The study has implications for the way forward to bring reforms in the system.

\section{Research Questions}

To achieve the stated objective of the study, the following research questions were formulated:

1. What is the quality of the available school data provided by different educational sources in the province of Punjab, Pakistan?

2. What is the usefulness of different school data sources for the stakeholders and school authorities in the province of Punjab?

3. What are the discrepancies found in various school data sources and how do they inform the school education system?

\section{Methodology}

This investigation is based on the explanatory sequential design of the mixed methods approach so that the obtained results could be described and presented in an improved and efficient way. For educational research processes, the mixed methods approach is more suitable and appropriate to examine the research problem for vigorous investigation (Mertens, 2014). It gives more 'accurate' results that could be obtained through multiple methods of data and provides a better understanding of the processes and events involved in the phenomenon (Creswell \& Creswell, 2017; Johnson \& Onwuegbuzie, 2004; Leech \& Onwuegbuzie, 2009; McMillan \& Schumacher, 2010). The findings gained through secondary quantitative data sources were not sufficient to validate the results.

After collecting the school data as a secondary source from different reports and statistical reviews by different educational organizations of the government of Punjab, they were presented and interpreted by the researchers. There were many contradictions in the data which needed to be further explored through interviews to get a deeper understanding of the discrepancies among various data. Hence, it was decided to conduct semi-structured interviews with the school teachers who were the producers, users and 'beneficiaries' of this data and they were assumed to be the best describers and interpreters of such data sources at the grass-root level. The teachers working in public schools were approached purposively and they participated in the interview sessions to give their input regarding the quality, authenticity and 'usefulness' of the available school data. This also helped to triangulate and validate the results of one method with another.

\section{Sample and Data Collection}

The study was conducted in the context of the province of Punjab, Pakistan. Two types of data were used. Firstly, we selected and analyzed data sets providing information regarding educational performance indicators and identified some 
flaws and discrepancies in the data sets that were being used in the decision-making process. Secondly, we conducted semi-structured interviews to gain a deeper understanding of these disparities and discrepancies in various school data sources. The focus group interviews were not possible as they did not ensure the confidentiality and anonymity of the participants of the study that could be risky for their professional life.

There were many data sources in the school education sector provided and maintained by different government organizations, UN organizations, International Non-government Organizations (INGOs), Local Non-government Organizations (NGOs) and Civil Society Organization (CSOs). We analyzed those data sources that included reports on Ranking of Districts issued by Punjab Education Sector Reform Program (PERSP), ninth-grade result gazette of Board of Intermediate and Secondary Education (BISE) Lahore and BISE Sahiwal, academic results of Punjab Examination Commission (PEC), The Annual Status of Education Report (ASER) 2015 and 2016, Alif Ailaan District Education Ranking (ADER) 2017 and few articles from newspapers.

Most of the data were available at Punjab level and interviews were conducted in district Lahore, Kasur, Okara, and Sahiwal because these were the main districts in BISE Sahiwal and BISE Lahore. We purposively selected eleven school teachers from these districts. They were engaged in teaching, students' assessment processes at PEC \& BISE and collecting the school data for school authorities. Analysis of quantitative data was performed manually because most of the data were available in the form of tables and statistics; we picked up those values and drew new tables where we found discrepancies in different data sets. For qualitative data gathered through semi-structured interviews, we used NVivo qualitative data analysis software. The qualitative data elaborated on the discrepancies found in numerical form from various school data sources. Later on, results were combined to get a more fruitful insight into the results of the study.

\section{Results}

The information derived from empirical studies confirms uncertainty and doubtfulness in the data. This information raised questions on the performance of PMIU and PEC and the use of data in decision making provided through these sources. The following results provide evidence for the uselessness of data used as a base for decision making.

\subsection{Asymmetrical Trends in the Ranking of Districts in Different Quarters}

Non-uniform tendencies of rankings in different quarters can be observed in data provided by PMIU (Program Monitoring and Implementation Unit) on quarterly rankings of different districts quarters (PESRP, 2015, 2016a, 2016b, 2016c, 2016d, 2017a, 2017b, 2017c, 2017d, 2018). We evaluated ranking data of those five districts which were at top position in the $3^{\text {rd }}$ quarter 2017-2018. We gathered and examined data for the last ten quarters of each district. It can be observed from Table 1 that the district which attained the top position in one quarter suddenly goes to the last position in the next quarter. In the same manner, a district which was at the lowest position in one quarter attains the first position in the next quarter. This is unbelievable and most surprising as it questions the validity of data. This is unjustifiable because the indicators that were considered to measure the rankings of districts do not support these results logically. Furthermore, the schools in all the districts cannot affect all the indicators in such a short period. For instance, what would possibly have happened to the internal structure and facilities provided by schools of a district in just one quarter that it dropped to the lowest position in the next quarter or vice versa? The same goes for other indicators such as attendance of teachers and students and disciplinary environment. Every indicator would require enough time and planning to improve. Suppose if we establish that our system is proficient enough to improve within a quarter then still it is not justified because the districts shift on both upward and downward. Why a district should choose to go at the lowest level after achieving the highest position even within three months. The level of facilities at school level is static and positively correlated with other indicators including students' presence and retention(AlifAilaan, 2017) but the ranking data shows its dynamic nature which is changing every quarter and so are its indicators.

During interviews with teachers, we explored that the data on different indicators is not "real" and don't represent the "actual" picture of performance by schools. Better districts should remain better throughout the year. The sudden change in rankings is not because of change in performance but it appears to be due to malfunctioning of processes used to collect data or data corruption on personal biases. Teachers didn't agree with the correctness of this data. One of the male teachers" "W" teaching mathematics in a secondary school described: 
"Instead of focusing on performance, learning and professional development of the teaches, district administration focuses only on getting better numbers on performance indicators. How they can get 'better figures' if they don't work on teachers' capacity building. I think they are more concerned about 'numbers and data' and not interested in school improvement in real sense"

We came to a very interesting conclusion about this matter described by the above participant that justifies the uselessness of data by inferring that it never happened that an officer from district administration came and assessed the level of learning by the class students. Every time they come and talk about school cleanliness, teachers and students' presence and ways of handling monitoring authorities. One of the male headteachers' "T" working in a middle school in the city shared minutes of a meeting with AEO (Assistant Education Officer) and remarked:

"The main points of the meeting revolved around the ways of "pleasing" the MEA (Monitoring and Evaluation Assistant) including politeness during the discussion, praising him, serving tea with quality biscuits. How one can rely on such a monitoring and evaluation system if the teachers are always pursuing to please the MEA. I think the school authorities should work on motivating teachers for quality teaching instead of making such useless monitoring"

The only purpose of these unnecessary activities is focused on not marking school with low numbers and not forwarding unsatisfactory reports.

Table 1: Quarterly ranking of top five districts of $3^{\text {rd }}$ quarter 2017-18

\begin{tabular}{lllllll}
\hline Year & Ranking & Okara & Bhakkar & Layyah & Attock & Sahiwal \\
\hline $2015-16$ & $2^{\text {nd }}$ & 24 & 35 & 15 & 8 & 28 \\
$2015-16$ & $3^{\text {rd }}$ & 1 & 35 & 3 & 12 & 28 \\
$2015-16$ & $4^{\text {th }}$ & 1 & 28 & 6 & 10 & 30 \\
$2016-17$ & $1^{\text {st }}$ & 1 & 13 & 18 & 25 & 26 \\
$2016-17$ & $2^{\text {nd }}$ & 3 & 6 & 10 & 12 & 29 \\
$2016-17$ & $3^{\text {rd }}$ & 1 & 17 & 11 & 7 & 31 \\
$2016-17$ & $4^{\text {th }}$ & 6 & 12 & 29 & 17 & 25 \\
$2017-18$ & $1^{\text {st }}$ & 18 & 2 & 21 & 17 & 12 \\
$2017-18$ & $2^{\text {nd }}$ & 1 & 2 & 6 & 5 & 15 \\
$2017-18$ & $3^{\text {rd }}$ & 1 & 2 & 3 & 4 & 5 \\
\hline
\end{tabular}

\subsection{Difference between Districts Rankings and PEC Results}

The data shows the difference between the results of data collected for the district ranking system and the Punjab Examination Commission (PEC) results. If a district is performing well throughout the year in all performance indicators including learning measured through the Literacy and Numeracy (LND) test, it must perform well in the final examination too.

But what we observed was entirely different and surprising. Districts that were placed at the top position in ranking scored low in PEC exams. While districts which were placed at lower positions scored high in PEC exams. The percentage of students passing PEC exams was lower in those districts which were at the top position according to data ranking while the percentage of students passing PEC exams was greater in districts that were at a lower position. For instance, PESRP issued district ranking in the year 2015-2016 according to which District Okara was at the top of the table because of its high performance (PESRP, 2015, 2016c, 2016d) but in PEC examination of that year, Okara's performance remained at 53.2\% (PEC, 2016).

Contrarily, district Layyah and Attock were placed at the middle position in ranking but they scored the highest according to performance which was 55\% and 64\% respectively in PEC exams (PEC, 2016). In the same way, the 
district Muzaffargarh was placed at the lowest position but students of this district performed well in PEC examination. The percentage of passed students was $64.67 \%$ (PEC, 2015). Surprisingly, this trend is common in almost every year of data. It seems to be unbelievable that a district that was placed at the highest position during the whole year would score less in the final examination. These types of discrepancies were found in many districts.

We interviewed teachers regarding these disparities and concluded that the results for both data sets are not real. The district which had more ability to exploit the assessment and measurement system got top position in the ranking. The same happened in PEC exam. The district which had more ability to manipulate the results of the examination system got a better position. One of the teachers" "F" who was fixing the responsibility of such malpractices was of the view:

"We all teachers agree to the fact that cheating is pervasive in PEC exams but we are not the only persons responsible for this undesired matter. District administration is fully involved in managing different techniques before, during and after the PEC exam to get the maximum results and attain the desired rank for a particular district."

Another teacher " $\mathrm{S}$ ' remarked surprisingly that "It is a tragic aspect of the matter that despite conducting prosecution against cheating, it is encouraged by the higher authorities"

The system of data collection was not free from errors and reliability. The number of students who took this exam from all 37 districts of Punjab was 2,549,680. These students belonged to both private and public sector schools. Out of $2,549,680$ students, 1,480366 belonged to $5^{\text {th }}$ grade and 1,069,314 belonged to $8^{\text {th }}$ grade (Sheikh, 2018). The whole process of assessment got less than two months. This is a very short time with limited available resources. This questions the credibility of the results. Moreover, this difference creates a state of confusion among teachers because, in the end, they are responsible for all performance indicators at the school. Many head teachers and teaching staff get involved in cheating at the time of examination and it also happens throughout the year at the time of data collection by PMIU.

\subsection{Difference between PEC and BISEs results}

In PEC exams in 2014 in Punjab, the percentage of passing students was 72\% (PEC, 2016). The same students who passed the PEC examinations when appeared in $9^{\text {th }}$-grade exams in the very next, only $39.86 \%$ passed the exam of BISE (Sahiwal, 2015). Results were the same in the rest of BISEs. Percentage of passing students in PEC exam 2015 was $74 \%$ (PEC, 2015) but same students when appeared in $9^{\text {th }}$ class exams, only $51.43 \%$ passed in BISE Sahiwal (BISE Sahiwal, 2016) and only 50.93\% passed in BISE Lahore in the $9^{\text {th }}$-grade exams $50.93 \%$ (BISE Lahore, 2016). Again in PEC exam 2016, $81 \%$ of students passed but the same number of students when appeared in $9^{\text {th }}$-grade exams of BISE Sahiwal and BISE Lahore, 53.21\% (BISE Sahiwal, 2017) and 54.21\% (BISE Lahore, 2017) students passed respectively. In 2017 94.55\% of students passed PEC exam (PEC, 2017) and in 2018 (PEC, 2018), 95.72\% of students passed PEC exam but the same students when appeared in $9^{\text {th }}$-grade exams, their results were not satisfactory. Almost the same happened in the very next year in 2019 (BISE Sahiwal, 2019; (BISE Lahore, 2019; PEC 2019; PEC 2020). What could be the reasons of this disparity, while only passed students got admission in $9^{\text {th }}$-grade?

From interviews with teachers, we established a few points. First, both assessment systems are different from each other. Mostly in PEC exam, the students are assessed on conceptual questions and don't follow the content of the course. On the other hand, in $9^{\text {th }}$ grade, question papers are restricted to the subject matter and strictly follow the content matter. This can be one of the reasons for many other factors. One of the teachers' "W" unveiled an interesting fact by stating:

"Seemingly the PEC assessment is difficult because it assumes no content of the course. On the other hand, secondary level students are more comfortable because of having content matter and fixed paper patterns. This shows that the success rate in PEC should be less than the secondary level but here we see opposite results. This fact makes PEC system suspicious and places question on its performance"

Secondly, most of the participants argued that PEC exams are supported by cheating practices by all the stakeholders of the education system while the chances of cheating in board examination are very rare. Students come with the 
previous perception of the PEC examinations of malpractices but face a different situation and lose their marks in BISE exams. Thirdly, the overall system from paper setting to marking is very lenient to support maximum students to pass. The so-called monitoring system also supports this situation. Lastly, almost every year the government promotes all students to the next grade up to elementary level. This creates a fuss of incompetent students at the secondary level that results in a low passing percentage at that level.

Table 2: Discrepancies in PEC and BISEs results of passed $9^{\text {th }}$-grade students in percentage

\begin{tabular}{llll}
\hline Year & PEC $8^{\text {th }}$ & BISE Sahiwal $9^{\text {th }}$ & BISE Lahore $9^{\text {th }}$ \\
\hline 2015 & 74 & 39.86 & 42.28 \\
2016 & 81 & 51.43 & 50.93 \\
2017 & 94.55 & 53.21 & 54.21 \\
2018 & 95.72 & 50.89 & 50.19 \\
2019 & 87.61 & 49.93 & 52.07 \\
\hline
\end{tabular}

\subsection{Deteriorating Learning Level}

Accuracy and usability of data provided by PMIU and PEC are also challenged by the deteriorating learning level of students presented in different data sets including ASER and AlifAilaan. It can be observed that the performance of district ranking system indicators is declining each year. The number of enrolled students has also risen. On the other hand, the learning level of students is declining every year (ASER, 2015, 2017). ASER published a report in 2015 according to which $30 \%$ of students of $5^{\text {th }}$ grade were unable to read a story from $2^{\text {nd }}$ class Urdu book. This percentage rose to $35 \%$ in the following year in contrast to last year. In the same way, the percentage of students of $3^{\text {rd }}$ grade who were unable to read a story from Urdu book was 72\% in 2015 and it jumped to $73 \%$ in 2016.

The capability to learn English was also descending every year. $43 \%$ of $5^{\text {th }}$-grade students were not capable of reading some sentences from grade two English books in 2016 while in 2015 the percentage was 40\%. It was also found out from the report that the percentage of students of three grade who were incapable of reading some sentences from class two English books was $80 \%$ in 2016 while it was $77 \%$ in 2015. Besides these subjects, some improvement was noted in the learning level of Mathematics. The percentage of $5^{\text {th }}$ class students who could not solve two-digit division questions was $41 \%$ in 2015 but in 2016 this level declined to 40\%. On the other hand, 77\% of three class students were incapable of performing two-digit divisions in 2015. This percentage rose to 80\% in 2016 (ASER, 2015, 2017; Sheikh, 2017). So far as the learning level is concerned, it is not increasing while students' achievement score in PEC exam is increasing every year and reached to $95.72 \%$ in 2018 .

To find out the reasons for this disparity we conducted interviews from teachers and concluded that the increase in achievement score does not predict learning level. This was data manipulation on behalf of stakeholders of the education to show increased results and to achieve quantitative targets. One of the male teachers" "A" who was teaching in English in a public school reflected:

"This seems entirely unnatural for an education system to produce a high percentage of success rate with the available system, sources, capacity building and the type of students we are teaching. The real result could be between 55 to 75 percent. This is the actual learning level of our students under the given quality teaching in our schools"

Additionally, another female participants' "Z" who was very critical about the existing school data was of the view, "All stakeholders including students, teachers, administration, PEC and monitoring system is involved in this practice and added to the provision of false data throughout the year." As a result, this showed increased results of the learning level rather than the actual one. A participant male teacher who had been assigned the additional duty of headmaster and was a very active person engaged in this process remarked:

"It would be surprising for you that schools make every effort to increase numbers throughout the year rather than increasing the learning level of students. Unfortunately, we are part of the system... you know... In my view, the school should arrange workshops in the area of content and innovative teaching methods to raise the 
quality of teaching rather than producing numbers"

The results indicate that data were suspicious and useless for the decision-making process. Another female school teacher "R" who was no more an acting school head reflected:

"I can understand the value of the decision that I took based on such school data when I was an acting head. I don't think such data can contribute to the real reform in the system. We need to face reality and take decisions that can make a difference"

The participants' conversation shows that they were aware of what was happening and some of them were not in favor of the system and wanted "real and positive changes".

\subsection{Students Openly Admit Cheating}

It was pathetic that cheating in PEC exam had become a common practice by most of the persons involved in this process of assessment. It was considered "normal" and students sitting in the examination hall already had expectations that someone from their school would come and provide them the helping material. Students at the primary and elementary levels admit to the claim of cheating. Teachers and administration members from PEC had been reported by the participants to be involved in all the available means of cheating to help the students at different examination centers to pass the examination in good grades (Khan, 2018).

Interviews with teachers established that as a result of consistent cheating every year a bad culture was promoting in the schools. They perceived that because of this culture a large number of students thought that they did not need to study or work hard during their academic year to pass the examination as they would be provided with the "helping material" needed to just pass the examination and they would be promoted to next grade. One of the teachers" "M" who involved in this assessment and had witnessed the system very closely described:

"Students start believing that teachers must help the students during PEC examination. They don't need to work hard to get passed in PEC examination. Being a teacher, I have witnessed and heard what students and parents remark about this system. I can't straightforwardly tell you"

Students who had taken PEC examination before telling their junior fellows about the center situation resulting in persuading them to believe that they would pass the examination entirely on the cheating basis. Another teacher "W" teaching mathematics to secondary and lower grades described:

"If we talk to the students regarding cheating, a large number of students would accept that they have cheated many times and only a small number of students would accept that they have cheated for once, but not even one student would say that he has not done this act"

This implies that the existing system of assessment is creating negative social values among the students and it would become harmful for the society in the future when they would enter into professional life based on such "false results". The other hard-working students and their parents are discouraged this way. One of the male school teachers " $F$ " whose children were also studying in the same school where he was teaching for the last ten years, described:

"It is also impacting brilliant students as they are disappointed after not getting good grades by their hardwork. They start disbelieving hard work because they know that their work would not be rewarded. As a teacher and father of my children, it is not acceptable for me. I am afraid that this system would spoil our next generation"

Such open admittance by the teachers and parents makes the provided school data useless as a base for future decisionmaking regarding students' learning progress and teaching output. 


\subsection{Secondary School Teachers' Fret}

Secondary school teachers are in a state of worry because of the difference between the results of PEC and BISE. They find students with more achievement scores and low learning levels. In this situation, it is very difficult for them to achieve the existing level of results in the intermediate examinations with this learning level of students. On the other hand, the authorities that manage these systems keep asking about why the percentage of passing students is low in intermediate (BISE) examinations in contrast to PEC exam. Furthermore, this creates an exhausting and conflicting condition between these two groups.

Since the students who pass PEC examinations fail to perform in the same way in the intermediate examinations held by BISE, the secondary school teachers do not enroll students based on PEC results. Teachers had to go through many problems when they had to select elective subjects for incoming students for enrollment in grade 11. The reason is that it is not confirming that a student with a high PEC score is hardworking and talented and is capable of studying science in the future because he might have got that high score based on cheating in the examination. We find teachers openly criticizing the system of PEC examination and school performance data collected by PMIU. This situation supports participants' notion about the uselessness of provided data for decision making.

Interviews with teachers also supported this claim. One of the secondary school teachers' " $T$ " who had a long experience of dealing with the students' entrance in secondary school while explaining the reasons for low results at the secondary level explained the situation with this interesting example. He exemplified metaphorically:

"If a shepherd has to move a herd of horses to a grazing area which is few kilometers away from his house. He will reach within minutes. On the other hand, if he has a herd consisting of few horses and many lazy sheep. He might not reach in time. Because the sheep would not allow him to run with his horses instead of crawling with his sheep"

He remarked that "same is happening with secondary school teachers." They receive students with low learning quality camouflaged in high achievement scores in PEC exam. Very few of them are capable enough to succeed in secondary school examinations held by BISE hence resulting in a huge gap between two examination systems.

\section{Discussion}

The discussion is based on the analysis of the school data obtained from the secondary sources and the participant teachers' interview data that reflected how this data was valid, authentic and useful for the subsequent decisions taken by the school management. It was inferred that data on the working capacity of schools and students' accomplishments collected through the Program Monitoring and Implementation Unit (PMIU) provides the basis for further decision making in the school education department. However, after analyzing data we found many contradictions about the quality and usefulness of provided data. Discussions with teachers endorsed the 'reality' of the uselessness of this data. It was noticed that using "unfair means" in the examination and practicing "academic dishonesty" is so widespread in our system that no result and data about school performance indicators are reliable to be used for the future decisionmaking process. There are many reasons behind this lethal activity for an educational system. Although the main focus of this analysis revolves around academic dishonesty supported by stakeholders of the school system, the findings explored a few situations in which schools were more likely to support cheating and academic dishonesty. Empirically, difficult and unrealistic task demands, incentive-based district ranking system for Executive District Officers (EDOs), ineffective monitoring system, scarce resources, curriculum above the students' level of understanding and untrained teachers are some of the key elements that compel school education department to depend on cheating strategies.

When school management is asked to achieve higher targets, it forces the schools to adopt cheating methods as an alternative because these schools and officials organizing these events are put under great pressure to produce good results. Students' attendance more than 90\%, teachers' attendance 100\% until Monitoring and Evaluation Assistant (MEA) completes his visit to school, Literacy, and Numeracy Drive (LND) test above 90\%, the results of Punjab Examination Commission (PEC) 90\%, and many other realistic and unrealistic expectations by the school authorities compel schools for using unauthorized and dishonest tactics. Most of the schools that are situated in villages have their problems. Education is not a priority of people. Students have to support their family in harvesting seasons and on many 
other occasions which continue throughout the year. Moreover, people are neither aware of the importance of education nor they have motivation for education.

How a school can attract and educate every child while having very little support from the government. International organizations and politicians point out the most complicated educational issues and order the officials to solve these issues without even understanding the intensity of issues and the authentic means to cope with them. Institutions are not free from political interference and they rely on "time taking strategy" by simply accepting the task. These heavy tasks flow down to schools. Now one problem is the difficulty of the task and the other is the achievement of a hundred percent results. Additionally, the schools are provided with very fewer resources to achieve the targets. Generally, evaluation is done based on the comparison between different cases.

Those schools which have a deficiency of resources will have greater hurdles in their path to attain the required targets. Contrarily, schools with sufficient and proper resources would attain the target easily. To be the part of the competition and to perform on equal levels, schools with deficient resources use cheating techniques thinking that they might be able to give the same results as that of schools with abundant resources. When districts have an aim to be at the top of the table of district rankings, chances of adoption of cheating methods are higher. In support such arguments one of the participants was of the view that "Incentive for $1^{\text {st }}$ position in district ranking is the root cause of every type of cheating". Monitory incentives are awarded to the EDOs of those districts who got $1^{\text {st }}$ position in the quarterly ranking. The attention of higher administration is on the "maximization of numbers" rather than concentrating on whether their actions are consistent with the true intent of the needs of the designed program. This can also be observed from PEC examination results of the last four years where results have jumped from $74 \%$ to $95 \%$. This is, in fact, the result of increased cheating and academic dishonesty for the sake of accomplishing the settled target. The ineffective monitoring system is a significant factor. Chances of cheating to occur are greater when daily routine activities are not strictly controlled. Our education system is highly decentralized. Supporting these arguments, one of the participant teachers' remarked, "Assistant Education Officer (AEO) visited our school two years ago. After that, he called headteacher with the school record to sign on what was performed by him."

Most of the headteachers remain busy in visiting higher authorities' offices every day for different so-called meetings. Monitoring and Evaluation Assistants' (MEAs) monthly visit is highly trapped as we discussed earlier. This lack of continuous and direct monitoring gives schools a great deal of discretion in how they perform duties. Knowing that they must achieve a certain level of targets; schools may use the absence of monitoring from administrations as an opportunity to cheat for maximizing required targets. Another side of the picture is that administration knows that they have fewer resources and less trained staff to achieve these targets. So, they support cheating. In this perspective, the participating teacher remarked:

"We all teachers agree to the fact that cheating is pervasive in PEC examinations. The more tragic thing is that despite conducting prosecution against cheating, it is encouraged by the higher authorities and we are doing even what we don't want to do... What else??"

Another teacher added, "We never feel confident and happy while supporting cheating in Examinations. We are forced to do so." From this understanding of the teachers, we can infer that higher authorities were well aware of the ability of this system and they knew that the system was unable to achieve the set targets that's why they supported unfair means in the examinations.

The curriculum is also above the students' mental level especially the curriculum of English. On of the English teacher was of the view, "It seems that no one evaluated the capacity of students and system before launching this curriculum". The study participants argued that most of the students were not able to understand the grammatical part of the syllabus which consist of a long-range of content and started from class three. English should be treated as a second language but unnecessary focus on it shows that it is treated as the first language. Additionally, teachers are not trained in modern teaching methods. The curriculum changed at the upper level but teachers know the only method of teaching by which they were taught themselves or they have learned about it many years ago. This lack of alignment results in low results. When schools are demanded big targets, they have the only option of academic dishonesty to achieve these targets. 


\section{Implications for Practice}

The study purported to examine the school data available in different sources and interpreting it to observe the prevailing discrepancies and to reflect that how such data can lead to the misguiding decision-making process. The discrepancies were also elaborated by the teachers participating in the study as interviewees. Given the results of the study, it has many implications for the educational and administrative practices and the reformation of the school education system in the province of Punjab, Pakistan.

Education policymakers should understand the importance of quality data by ensuring that data remains a vehicle for effective decisions rather than an impediment to achieving educational success in this globalized world. The quality of products depends on the process by which products are designed and produced. Similarly, the quality of data depends on the design and production processes involved in data collection. To design for better data quality, an education system must value what data quality means and how to measure it accurately. Data quality management should be a continual process in this era of technological changes. It may happen that high-quality data today may become lowquality data tomorrow. Data collection systems' designs and operational procedures require a continual focus and follow up. New structures should be added to inherent systems based on multiple dimensions of data quality by defining, assessing, modifying and redefining the meaning of data quality and how it can best be managed.

Assessment doesn't guarantee perfection in data. A functioning mechanism to recognize, evaluate and report the degree of ambiguity in the reported data is required rather than declare all the data flawed. The amount of error in the decisions made based or erroneous data should also be recognized, evaluated and reported. Additionally, the use of multiple assessment and performance measurement systems (rather than a single one) can enable policymakers to understand and take into consideration the nature and magnitude of errors in the data. A comprehensive school information system is needed that can enable providing quality data on school inputs, processes and outputs respectively.

Contextual differences among different schools demand autonomy in decision making at the school level. Different schools of different districts even schools of the same district are running in entirely different local environments. It is the basic requirement of every school that there should be autonomy in making decisions. The targets to be achieved by the school are then set according to the decisions and rules set by administration units providing equal facilities to all the schools. But the current system sets the same targets for different schools given unequal facilities. Schools' efforts are restricted to a few preset standards only. Additionally, it places more focus on the comparison of performance from school to school and district to the district rather from year to year. This doesn't allow for differences in the starting point and to maintain equal expectations from all. If they have autonomy in decision-making, they would establish and maintain databases that could be manipulated in response to a variety of situations. If the data are meaningful at the school level, it is more likely to impact the quality of decision and education. To make decisions at school levels, data usage would increase, so attention to the accuracy of data should increase.

To achieve quality data, we should stop measuring students and school performance on a few quantitative performance targets. Throughout the years, all schools' efforts center on achieving targets of Program Monitoring and Implementation Unit (PMIU) and other examination-oriented targets and little is being done on improving many important aspects of student' development. In doing so, the schools overlook many developmental tasks including character building, social interaction, motivation, personality development, innovation in teaching-learning and extracurricular activities. it is clear from the above debate that schools are involved in organizational cheating and produce numbers only on few indicators.

The results also imply thinking about the performance level of our monitoring system. The government is spending a lot of resources on this system. It is a scrupulous and consistent program to monitor and collect data on different school performance indicators. There is a provincial level hierarchy to monitor the performance of schools. It is achieved through the visits of MEAs on monthly basis. Despite all efforts being made, there are questions on the usefulness and trustworthiness of collected data. The correctness of data provided by PEC and PMIU is needed to be audited by some third party which can be a national as well as an international NGO working in this field. The existing gap in the accuracy of available data can be addressed by comparing the results of different data sources for cross-verification. It is also recommended that universities should also assist the government by initiating different research projects on 
this important issue. Instead of that they continue replicated research work which is mostly useless for the development of the society; they should research indigenous educational problems. For instance, we have many large educational departments in different universities but unfortunately, no one has his data source on any single educational field. This can be considered and we should initiate work on building a dynamic data collection mechanism on different educational performance indicators at each level. The whole process should also be funded by the government to get more fruitful results.

Lack of coordination between different institutes and organizations is also a major contributor to this problem. There must be coordination within an institution from bottom to the upper level and also between different organizations. Local and international NGOs should also be attached to the system. There must be a check on their results and the results by them should be triangulated. Last but not the least, there is a dire need to investigate the motivation behind doing so. After all, every act is performed by humans and humans always have some sort of motivation behind every act. We should investigate motivational factors behind this organizational and examination cheating through a careful investigation. Resultantly, a policy should be launched that can effectively address those motivational factors to minimize its negative consequences and should address these problems with some solutions.

\section{Conclusion}

Given the discussion and implications for the way forward, it can be concluded that the available methods of collecting public-school data in the province of Punjab, Pakistan does not seem to be reliable and it does not reflect accurate, complete, consistent and timely-gathered data about the 'real' working capacity of schools. Unfortunately, the schools and education authorities are 'blindly' relying on this data in the decision-making process that is risky for bringing 'productive' reforms in the school education system. The data on school performance indicators and PEC results were found contradictory on the bases of six shreds of evidence. Firstly, asymmetrical trends in quarterly rankings of different districts were observed which cannot be justified. Secondly, the difference between district rankings and PEC results shows contradictions in data sets. Thirdly, the difference between the performance of districts measured by the data collected through PMIU and PEC results shows a discrepancy in academic performance. Fourthly, the difference between PEC and BISEs results shows a disparity in achievement levels of both the examination agencies. Fifthly, students openly admittance of cheating in PEC examination questions the trustworthiness of data provided by PEC. Lastly, secondary school teachers' fret regarding the discrepancy in the learning ability of students having high scores in PEC examinations and low achievement in $9^{\text {th }}$ grade (BISE examination) challenged the authenticity of performance standards revealed in PMIU and PEC data. The authorities should look into these discrepancies and design the policies that can guide the valid data collection strategies and quality measures of school improvement.

\section{References}

Alif Ailaan. (2017). Pakistan District Education Ranking 2017. Retrieved from: https://elections.alifailaan.pk/wpincludes/file/DER17.pdf

ASER. (2015). Annual Status of Education Report 2015.

ASER. (2017). Annual Status of Education Report 2016.

BISE(Lahore). (2016). Result Gazette, Secondary School Certificate (9th Class), Annual Examination. Lahore.

BISE(Lahore). (2017). Result Gazette, Secondary School Certificate (9th Class), Annual Examination. Lahore.

BISE(Lahore). (2018). Result Gazette, Secondary School Certificate (9th Class), Annual Examination. Lahore.

BISE(Lahore). (2019). Result Gazette, Secondary School Certificate (9th Class), Annual Examination. Lahore.

BISE(Sahiwal). (2015). Result Gazette, Secondary School Certificate (9th Class), Annual Examination. Lahore: Retrieved from http://bisesahiwal.edu.pk/.

BISE(Sahiwal). (2016). Result Gazette, Secondary School Certificate (9th Class), Annual Examination. Lahore: Retrieved from http://bisesahiwal.edu.pk/.

BISE(Sahiwal). (2017). Result Gazette, Secondary School Certificate (9th Class), Annual Examination. Lahore: Retrieved from http://bisesahiwal.edu.pk/.

BISE(Sahiwal). (2018). Result Gazette, Secondary School Certificate (9th Class), Annual Examination. Lahore: Retrieved from http://bisesahiwal.edu.pk/.

BISE(Sahiwal). (2019). Result Gazette, Secondary School Certificate (9th Class), Annual Examination. Lahore: Retrieved from http://bisesahiwal.edu.pk/. 
Bohte, J., \& Meier, K. J. (2000). Goal displacement: Assessing the motivation for organizational cheating. Public Administration Review, 60(2), 173-182.

Bouckaert, G., \& Peters, B. G. (2002). Performance measurement and management: The Achilles' heel in administrative modernization. Public performance \& management review, 25(4), 359-362.

Creswell, J. W., \& Creswell, J. D. (2017). Research design: Qualitative, quantitative, and mixed methods approaches: Sage publications.

Dalton, B. (2017). RTI Press.

Johnson, R. B., \& Onwuegbuzie, A. J. (2004). Mixed methods research: A research paradigm whose time has come. Educational researcher, 33(7), 14-26.

Juran, J. M. (1988). Juran on planning for quality: Collier Macmillan.

Khan, W. A. (2018). Fake Assessment and Punjab Examination Comission. Retrieved June 5, 2018, from http://www.khanwaqas.com/fake-assessment-punjab-examination-commission/articles.html

Leech, N. L., \& Onwuegbuzie, A. J. (2009). A typology of mixed methods research designs. Quality \& quantity, 43(2), 265-275.

Mandinach, E. B., Honey, M., \& Light, D. (2006). A theoretical framework for data-driven decision making. Paper presented at the annual meeting of the American Educational Research Association, San Francisco, CA.

Marsh, J. A., Pane, J. F., \& Hamilton, L. S. (2006). Making sense of data-driven decision making in education.

McMillan, J. H., \& Schumacher, S. (2010). Research in Education: Evidence-Based Inquiry, MyEducationLab Series. Pearson.

Mertens, D. M. (2014). Research and evaluation in education and psychology: Integrating diversity with quantitative, qualitative, and mixed methods: Sage publications.

Miller, H. (1996). The multiple dimensions of information quality. Information Systems Management, 13(2), 79-82.

Muriel, A., \& Smith, J. (2011). On educational performance measures. Fiscal Studies, 32(2), 187-206.

Ozga, J. (2003). Measuring \& Managing Performance in Education: Citeseer.

PEC. (2015). Punjab Examination Commission Report on Grade 5 \& 8 Examination. Lahore: Retrieved from http://www.pec.edu.pk/system/files/PEC\%20Report\%20R7 0.pdf.

PEC. (2016). Punjab Examination Commission Report on Grade 5 \& 8 Examination. Lahore: Retrieved from Downloads\Documents\PEC_Exam_Analysis_Report_2016.pdf.

PEC. (2017). Result Gazette, Annual Examination.

PEC. (2018). Result Gazette, Annual Examination.

PEC. (2019). Result Gazette, Annual Examination.

PEC. (2020). Result Gazette, Annual Examination.

PERSP. Retrieved June 3, 2018, from http://www.pesrp.edu.pk/home

PESRP. (2015). District Education Ranking $2^{\text {nd }}$ quarter http://www.pesrp.edu.pk/datacenter\#district_ranking

PESRP. (2016a). District Education Ranking http://www.pesrp.edu.pk/datacenter\#district_ranking

PESRP. (2016b). District Education Ranking http://www.pesrp.edu.pk/datacenter\#district_ranking

PESRP. (2016c). District Education Ranking http://www.pesrp.edu.pk/datacenter\#district_ranking

PESRP. (2016d). District Education Ranking http://www.pesrp.edu.pk/datacenter\#district_ranking

PESRP. (2017a). District Education Ranking http://www.pesrp.edu.pk/datacenter\#district ranking

PESRP. (2017b). District Education Ranking http://www.pesrp.edu.pk/datacenter\#district ranking

PESRP. (2017c). District Education Ranking http://www.pesrp.edu.pk/datacenter\#district ranking

PESRP. (2017d). District Education Ranking http://www.pesrp.edu.pk/datacenter\#district_ranking $1^{\text {st }} \quad$ quarter

$2^{\text {nd }} \quad$ quarter

$3^{\text {rd }}$ quarter

$4^{\text {th }} \quad$ quarter

$1^{\text {st }} \quad$ quarter

$2^{\text {nd }} \quad$ quarter

$3^{\text {rd }} \quad$ quarter

$4^{\text {th }} \quad$ quarter
2015-16.

2016-17.

2016-17.

2015-16.

2015-16.

2017-18.

2017-18.

2016-17.

2016-17.
Retrieved

from:

Retrieved from:

Retrieved from:

Retrieved from:

Retrieved from:

Retrieved from:

Retrieved from:

Retrieved from:

Retrieved from: 
PESRP. (2018). District Education Ranking $3^{\text {rd }}$ quarter 2017-18. Retrieved from: http://www.pesrp.edu.pk/datacenter\#district_ranking

Pipino, L. L., Lee, Y. W., \& Wang, R. Y. (2002). Data quality assessment. Communications of the ACM, 45(4), 211218.

Popham, W. J. (1987). The merits of measurement-driven instruction. The Phi Delta Kappan, 68(9), 679-682.

Popham, W. J., Cruse, K. L., Rankin, S. C., Sandifer, P. D., \& Williams, P. L. (1985). Measurement-driven instruction: It's on the road. The Phi Delta Kappan, 66(9), 628-634.

Qambar,G., Farooqi,M.T.K., \& Ather, H.M. (2018). Impact of district ranking system on students' achievement score in PEC exam. Global Social Sciences Review, 3(1), 243-262

Senge, P. M. (1990). The art and practice of the learning organization: New York: Doubleday.

Shankaranarayanan, G., \& Cai, Y. (2006). Supporting data quality management in decision-making. Decision Support Systems, 42(1), 302-317.

Sheikh, A. (2017). Rural Punjab Enrolment Up but Standards deteriorate The Express Tribune. Retrieved from https://epaper.tribune.com.pk/DisplayDetails.aspx?ENI_ID=11201709140030\&EN_ID=11201709140016\&E $\mathrm{MID}=11201709140006$

Sheikh, A. (2018, April 1, 2018). More than 80\% pass PEC grade 5, 8 examinations, TRIBUNE. Retrieved from https://tribune.com.pk/story/1674420/1-80-pass-pec-grade-5-8-examinations/

Shewhart, W. A., \& Deming, W. E. (1986). Statistical method from the viewpoint of quality control: Courier Corporation.

Wand, Y., \& Wang, R. Y. (1996). Anchoring data quality dimensions in ontological foundations. Communications of the ACM, 39(11), 86-95.

Wang, R. Y., Ziad, M., \& Lee, Y. W. (2006). Data quality (Vol. 23): Springer Science \& Business Media. 